\title{
ASSESSMENT OF THE EFFECT OF INTEGRATION REALISATION IN CONSTRUCTION PROJECTS
}

\author{
Roman TRACH, Marzena LENDO-SIWICKA, Katarzyna PAWLUK, Nina BILOUS
}

\begin{abstract}
The aim of the article is to develop an assessment model for the effect received from the integration of enterprises during the realization of investment projects in the construction. Having analysed the existing methods of the economic effect evaluation, we came to the conclusion that it is impossible to use them completely to assess the economic effect of the integration of enterprises during the investment projects in the construction. In the case of an integrated realization of a project in the construction sector, it is the information and communication links that are combined, and not the enterprises themselves. In addition to that, not all models take into account the synergistic effect. To solve the above-mentioned problem, we analysed the advantages gained by participants during the realization of the integrated project in construction and the benefits that have the greatest impact on the synergy effect. The calculation of the effect of the information and communication system management and the innovative nature of the process of its implementation suggest that this process has a clear investment component. Consequently, the process of enterprise integration should be considered as an investment project implemented at the level of network association.
\end{abstract}

Keywords: construction project; information and communication system; integration; synergetic effect

\section{INTRODUCTION}

The questions of cooperation and integration during the delivery process were a great concern of scientists for a long period. For instance, it recalls how the separation of the design and construction phases of projects was identified as a problem by government industry reports in the UK as early as 1962 by Emerson, who identified how removed the responsibility for design is from the responsibility of production [1]. He suggests that the procurement models which omit the contractor can increase risk, reduce communication between team members, cause delays and create incorrect information which can lead to disputes and claims. The importance of the integration processes was emphasized by Chinowsky [2] who developed what is called an "Integration Matrix" (Fig. 1).

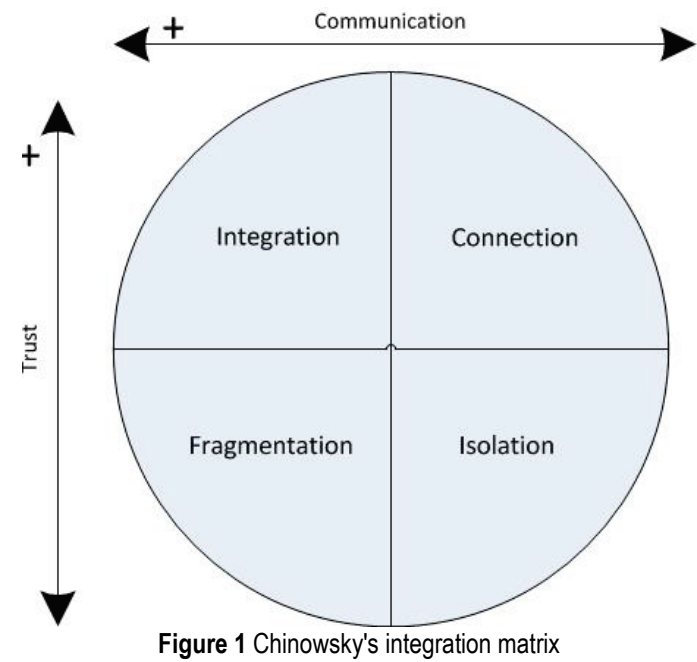

Figure 1 Chinowsky's integration matrix

\section{LEVELS OF INTEGRATION IN CONSTRUCTION}

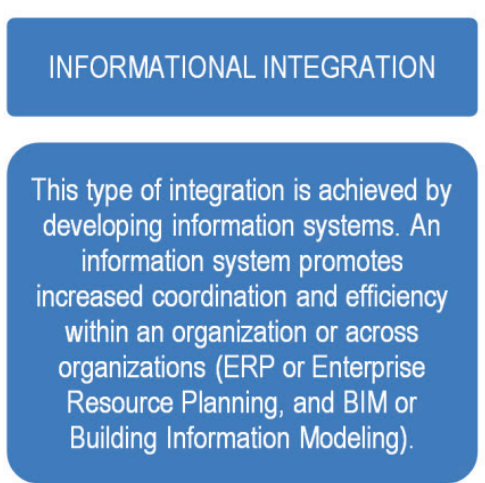

CONTRACTUAL INTEGRATION

Contractual integration evolved in response to the need for better communication, avoid

misunderstandings and eventual

litigation. Contractual integration is

best achieved by adopting techniques that reduce the needs of bureaucracy,

or implementing procedures based on trust.

Figure 2 Levels of integration in construction

The four quadrants of the matrix refer to the varying levels of trust and communication. The final state is that of integration, where both trust and communication levels are high. They note that this is the preferred state for collaboration to occur. The concept of high performance is routinely implemented in diverse industries but has received 
little attention in the construction industry, where success is typically measured using traditional indicators, such as time, cost and quality. Authors suggests that the problem can be addressed by viewing the construction team as an integrated group of participants within a network, rather than as a group of participants. The team needs to consist of a cohesive network where members focus on building long term relationships that are transferred from activity to activity.

The project delivery method is selected by the owner of the construction project. That method establishes the preconditions for the realization of the project, such as the roles and responsibilities of the participants, including the legal agreements between the parties by setting the project target and payment method. This tends to be a critical factor so if selected correctly, it enables the successful implementation of a construction project. Fig. 2 shows three levels of integration in construction.

The aim of the article is to develop the assessment model for the effect received from the integration of enterprises during project delivery in construction.

\section{MATERIALS AND METHODS}

Network structures have different configurations including heterogeneous elements that provide the highest level of collaboration. Such elements in each particular case have their own unique list that provides the energy of cooperation in each particular situation. The overall economic effect depends not only on the elements the network consists of, but also on the nature and quality of the links between them.

In modern economic conditions, the decision on the economic agents' integration considerably allows the change of the competitive position of the enterprise. The integration process leads to new subsystem formation and the interconnections between them. At the same time, the interaction and influence of the subsystems in an integrated structure is characterized by the emergence of a new synergetic component, which is considered to be the effect of enterprise integration, and is the basis of the goals and motives of integration. The synergistic effect presence means that the result of the integrated system of enterprises is higher than the sum of the results of individually operating enterprises united in the process of integration. Depending on synergy effect it can evaluate the effectiveness of the integration itself.

The efficiency of the integration process depends largely on how effectively the management of various forms of interaction between construction enterprises is carried out. The results of the integrated enterprise's production processes are not always clear and, in some cases, can lead to an efficiency decrease, because the enterprises do not fully use the potential of business units' interaction and the additional effects are the results of such potential. If the interaction of enterprises within the framework of integrated structures does not provide the desired effects, it is important to update the methodological approaches that help improve the mechanism of the integrated structures management. The presence or absence of economic connections with certain characteristics affords ground for affirming or denying the existence of a network structure. In our opinion, it is the interrelationships that can be distinguished from the general system of elements and can be used as the basis for identifying the network organizational structures. This is especially important for the network structures of the investment and construction complex, since they are characterized by the absence of legal consolidation of integration relationships, such as participation in capital, the transfer of property rights between economic entities.

The effect of network interaction between enterprises has its own specifics. It is not only the effect of consolidation because enterprises retain some independence (there is no saving in management costs, for instant, because the management apparatus of each of the enterprises remains the same). At the same time, a systemic dynamic should arise in the process of interaction and should become the consequence of it. It means that the coordinated work of independent companies provides an additional synergetic effect of the system interaction as a whole.

The investigation of the synergy phenomenon began to develop with the activation of integration processes in the economy, although the very point of the synergetic effect was described by Aristotle. In the IV century BC, he noted that "the whole is greater than the sum of its parts" [3]. I. Ansoff defined the synergy effect as the possibility of getting the better economic effect from the joint work of several business units in comparison with the results of their independent activity [4]. In his concept of synergy, he focuses on the role the economic base has, on the potential of material and non-material assets and their close connection with the potential of the enterprise.

$\mathrm{X}$. Itami considered that the synergy effect received from integration is a result of resource utilization efficiency and it is growing in an integrated corporation in comparison to their use by companies before integration [5]. He identified two types of resources: physical resources (fixed assets, inventories, etc.) and intangible assets (brand, technology and know-how, corporate culture, etc.). In his opinion, two types of effects can be formed as a result of integration:

- complementary effect which refers to the improvement of physical resources usage (the corporation uses its resource potential in full),

- synergetic effect which is achieved only by using invisible assets.

In our opinion, using a network organizational structure during the delivery process in the construction industry has the most interesting and at the same time the most difficult issue to study. It is the issue of information synergy evaluation that is formed due to the optimization of information and communication management.

The analysis of theoretical and practical research in the field of economic entities integration $[6,7,8]$ showed that the efficiency of integration is mainly assessed by minimizing the costs of the enterprises (they are transactions in most cases). In this article, only this approach is not sufficient, since it is planned to assess the efficiency of integration not only from the position of the interacting entities themselves, 
but also from the position of the whole integrated system, within the framework of their interests and its coordination. It is expedient to assess the "cumulative effect" of acts of initiating integration chains of interaction between the socioeconomic entities during project delivery in construction. Such effect can be evaluated only within the framework of a synergetic approach to integration evaluation.

Synergy can be classified according to the impact on the company's cash flows $[9,10]$ (Fig. 3 ).

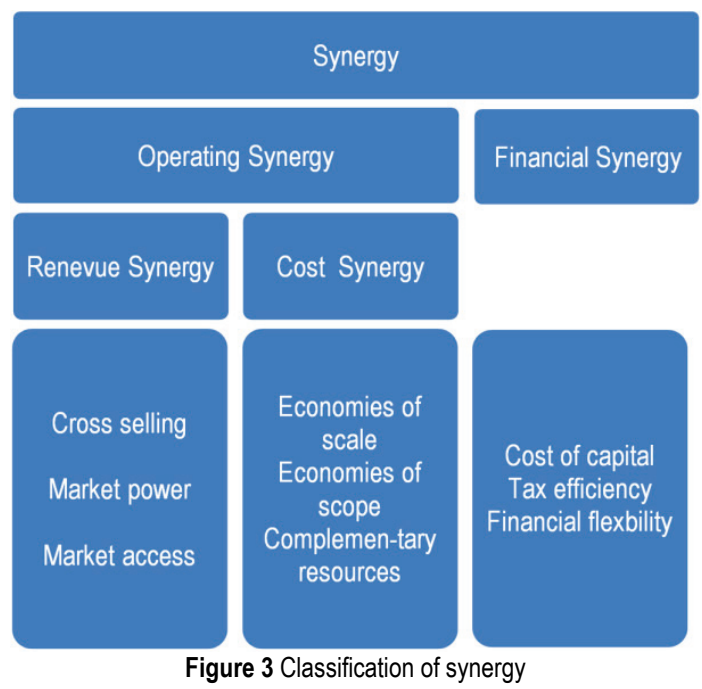

One of the main methods for synergistic effect evaluation is to compare the value of integrated enterprises, before and after their combination [11-13]. Net Assets Value Method, Market Method and Capital Assets Pricing Method can be used in this case. The Net Assets Value method is often used in takeovers and mergers and includes a set of methods to assess the value of enterprises, based on the costs that are necessary to restore the object of takeover. The main principle on which this method is based is the principle of substitution. It means that the buyer will never acquire an object at a price exceeding the cost of acquiring or reproducing an object similar in its consumer characteristics. This approach does not allow taking into account the changes in performance indicators in future periods. A typical example of the net assets' value method is the method proposed by A. Damodoran, who determines the synergetic effect as a result of exceeding the value of integrated companies over the sum of the companies' value before integration [14]. In particular, the Net Acquisition Value, $\mathrm{NAV}$, is calculated according to the following formula:

$$
N A V=\left[V_{i j}-\left(V_{i}+V_{j}\right)\right]-(P+E)
$$

Using the following notations: $V_{i j}$ - the value of the combined firms $i$ and $j ; V_{i}$ - the value of the standalone firm $I ; V_{j}$ - the value of the standalone firm $j ; P$ - the premium paid for the acquisition; $E$ - the amount of expenses engaged in the acquisition process.
The value in $V_{i j}-\left(V_{i}+V_{j}\right)$ is a synergistic effect. To recoup the integration, this effect should be greater than the sum $(P+E)$.

Methods that are used in the framework of the comparative approach make it possible to compare the assessed object with similar objects and on this basis, to establish its value. A comparative approach can be used for both market valuation and the valuation of investment value. However, since there are no two absolutely identical associations, some average market multipliers are expertly determined and used to calculate the cost using comparative approach methods and that reduces the accuracy of the results.

In practice, the Capital Assets Pricing Method is used more often and it gives the most objective assessment of the effect received from the integration. In this approach, the discounted cash flow method is used to estimate the value of the company. The very core of the method is to determine the current value of cash flows that will be received in the future. In the framework of the Capital Assets Pricing Method, there are a significant number of models suitable to calculate the economic effect.

In particular, S. A. Orekhov [15] calculates the effect received from integration into the holding structure as follows:

$$
C_{n}=D(P N)_{n}+D(P A)_{n}+(E E)_{n}-D I_{n}+D T_{n}-I_{o}
$$

Where: $n$ - the calculated period of time; $D(P N)_{n}$ - the additional profit received from activity expansion; $D(P A)_{n}$ the additional profit taken from risk reduction due to the diversification of the holding's activities; $(E E)_{n}$ - the saving current production costs; $D I_{n}$ - the additional investments for reconstruction and expansion; $D T_{n}$ - the increase (saving) of tax payments; $I_{o}$ - the investments at the time of takeover.

A number of authors [16] propose to use the method of discounted cash flows in the framework of this approach. The synergistic effect is calculated in accordance with:

$S=\sum_{t=1}^{T} \frac{\Delta C F_{t}}{(1+R)^{t}}$

Where: $\Delta C F_{t}$ - the difference between the cash flows of the integrated company and the amount of cash flows of each company separately before the time $t ; R$ - the mathematical discount factor expectation that is calculated according to the planned rate of return to the net worth of the company that is taken over.

The increase in cash flows is as follows:

$\Delta C F_{t}=\Delta R_{t}-\Delta C_{t}-\Delta T_{t}-\Delta I_{t}$

Where: $\Delta R_{t}$ - the increase of the income received from the takeover; $\Delta C_{t}$ - the increase in costs; $\Delta T_{t}$ - the increase in tax payments; $\Delta I_{t}$ - the increase of additional working capital investments and fixed assets. 
Having analysed the above methods and approaches, we can conclude that they cannot be fully used to evaluate the effect received from enterprise integration during project delivery in construction, since the vast majority of these methods are based on the analysis of enterprise amalgamation and their cash flows after the takeover. In the case of integrated project delivery in the construction industry, it is the information and communication links that are united, but not the enterprises themselves. Additionally, the synergistic (immaterial) effect is not taken into account in all models. Moreover, it is necessary to distinguish more clearly between the terms of economic effect evaluation and integration and the synergetic effect which is one of the main factors, but not the only one.

\section{$3 \quad$ RESULTS AND DISCUSSIONS}

This article proposes, in the framework of the synergetic approach, to take the ratio of the additional income received from the association of enterprises to the costs on this project delivery as a criterion for the economic efficiency of enterprise integration programs.

The calculation of the economic effect received from managing the information and communication system and the innovative character of the process of its implementation shows that this process has a clear investment component. Therefore, the process of enterprise integration should be considered as an investment project delivered at the level of a network association. Accordingly, regarding the innovative process of the information and communication system network model realization, the predictive efficiency of investments can be expressed by the following economic and mathematical dependence:

$$
E_{t}=\frac{\sum_{i=1}^{m} \frac{I_{t}}{\left(1+n_{t}\right)^{t}}}{\sum_{i=1}^{m} \frac{C I_{t}}{\left(1+n_{t}\right)^{t}}+\sum_{i=1}^{m} \frac{C O_{t}}{\left(1+n_{t}\right)^{t}}}
$$

Where: $E_{t}$ - the efficiency of the information and communication system operation in the integrated project delivery over a period of time; $I_{t}$ - the total revenue stream that the integrated enterprise receives from the information and communication system implementation over a period of time; $C I_{t}$ - the investment costs that the enterprise spends to launch and implement the integrated information and communication system; $\mathrm{CO}_{t}$ - the operational costs to manage the information and communication system of the business entity; $t$ - the analysed period of time; $n_{t}$ - the rate of discounting accepted for calculations; $m$ - the number of enterprises that integrate.

The synergy effect calculation is the most difficult part in the total revenue stream calculation. It is possible to use various factors to assess the synergy, and their sum-total is formed according to the direction and the logic of the research. Therefore, it is a situation similar to the economic efficiency integration evaluation, namely the isolation of the effects that are indicative for the integrated project delivery in construction. Taking into account the specifics of this research, namely, the evaluation of the effect formed after the information and communication system introduction in the integrated project delivery in construction, we can identify the following synergistic effects:

$$
I_{t}=\sum \Delta S=S_{1}+S_{2}+S_{3}+S_{4}+S_{5}+S_{6}
$$

Where: $\Delta S$ - the synergy effect, which is formed from the introduction of the information and communication system in the integrated project delivery; $S_{1}$ - the synergetic effect formed from reducing the number of errors and collisions in the construction project delivery; $S_{2}$ - the synergistic effect from the overall reduction of project duration due to a higher coordination of actions; $S_{3}$ - the synergistic effect of transaction costs reduction; $S_{4}$ - the synergetic effect from the cost reduction at the stage of facilities' management; $S_{5}$ - the synergistic effect of a new value creation; $S_{6}$ - the synergistic effect from the production scale increase.

The next stage is the analysis of the cost structure connected with the integrated project delivery. The expenses can be divided into two parts, the sustainable (investment) and variable (operational) costs.

The structure of investment expenses is determined by the task to introduce the integrated model into the network organizational structure of enterprises and is as follows:

$$
\begin{aligned}
& C I_{t}=\left[\sum_{i=1}^{y}\left(C_{e} * T_{s b a s}+C_{s t}\right)+C I_{c e}+C I_{s}+C I_{d b}\right]+ \\
& +\sum_{i=1}^{j}\left(C_{a s} * T_{\text {adapt }}\right)
\end{aligned}
$$

Where: $C_{e}$ - the average wage rate of an employee who is having the training; $T_{s \text { bas }}$ - the time of training, one employee coordination and workplace integration; $C_{s t}$ - the average cost of training; $C I_{c e}$ - the investment costs for computer equipment acquisition; $C I_{c e}$ - the investment costs for software acquisition; $C I_{d b}$ - the investment costs for database acquisition; $C_{a s}$ - the average wage rate of the project manager assistant; $T_{\text {adapt }}$ - the time the assistant needs to adapt in an integrated system; $y$ - the number of employees and workplaces integrated into the system; $j$ - the number of the project manager "assistant".

As it is seen from the expression (7), investment costs can be divided into the following three groups:

1) the costs of training for the employees to learn the new innovative model of network relationships (including both the costs of pay for those who conduct training and the loss of time during the training period when the employees of the enterprise are not engaged in the performance of their immediate duties);

2) the expenses for the computer equipment, software and database acquisition and adaptation;

3) the costs to adapt the project manager assistant to the integrated system. 
The first two groups of expenses are reflected in the formula (7) in square brackets and include the training, computer equipment, software and database acquisition for all employees participating in the integrated process. The third term presents the expenses for the project manager "assistant".

Operating costs are given in the following expression:

$$
\begin{aligned}
& C O_{t}=\sum_{i=1}^{y}\left(C O_{c e}+C O_{s}+C O_{d b}\right)+\sum_{i=1}^{j}\left(C_{a s} * T_{w}\right)+ \\
& +\sum_{i=1}^{x}\left(C_{t} * T_{\text {s add }}\right)
\end{aligned}
$$

Where: $\mathrm{CO}_{c e}$ - the operating costs for computer services;
$C O_{s}$ - the operating costs for software maintenance; $C O_{d b}$ is the operating costs for database maintenance; $T_{w}$ - the project manager assistant work duration; $T_{\text {sadd }}$ - the time for additional training, consultation and formalization of knowledge for the employee; $x$ - the number of employees who need additional training and consultations.

$m$ - the duration of the project, years.

They also form three clear groups:

1) expenses for computer services, software and database maintenance; assistant

2) expenses for the salary of the project manager

3) expenses for the additional training, consultations and formalization of knowledge for employees.

Taking into account the expressions (6)-(8), the formula (5) can be expressed by the following economicmathematical dependence:

$$
E_{t}=\frac{\sum_{i=1}^{m} \frac{S_{1}+S_{2}+S_{3}+S_{4}+S_{5}+S_{6}}{\left(1+n_{t}\right)^{t}}}{\sum_{i=1}^{m} \frac{\left[\sum_{i=1}^{y}\left(C_{e} * T_{s ~ b a s}+C_{s t}\right)+C I_{c e}+C I_{s}+C I_{d b}\right]+\sum_{i=1}^{j}\left(C_{a s} * T_{a d a p t}\right)}{\left(1+n_{t}\right)^{t}}+\sum_{i=1}^{m} \frac{\sum_{i=1}^{y}\left(C O_{c e}+C O_{s}+C O_{d b}\right)+\sum_{i=1}^{j}\left(C_{a s} * T_{w}\right)+\sum_{i=1}^{x}\left(C_{t} * T_{s a d d}\right)}{\left(1+n_{t}\right)^{t}}}
$$

The predictive efficiency indicator $E_{t}$ of the information and communication structure integration during project delivery in construction should not be less than one. At the same time, the value $E_{t}>1$ indicates a positive effect of innovation.

\section{CONCLUSIONS}

A system of economic and mathematical dependencies has therefore been formed to assess the effect of enterprise integration during project delivery in construction. The criterion for the efficiency of enterprise integration programs is the ratio of the additional income received from the association of enterprises to the costs on this project delivery. The additional income is the total synergistic effect that the integrated enterprise receives from the information and communication system implementation. The costs is the sustainable (investment) and variable (operational) costs on this project delivery. The paper proposes how to solve the issue of separating the share, which is formed as a result of integration processes, from the general effects of the enterprise's economic activity. Finally, the advantages obtained by the participants of the integrated project in construction are analyzed and the advantages that have the greatest impact on the synergistic effect are highlighted. In our opinion, it is warranted to use projections to make a decision on integration, and retrospective evaluation should be used to determine how well the business combination operates. Further studies will be related to the practical application of the model proposed to evaluate the economic effect received from the integration of enterprises during project delivery in construction.

\section{Abbreviations}

NAV - Net Acquisition Value

ERP - Enterprise Resource Planning

BIM - Building Information Modelling

\section{REFERENCES}

[1] Mosey, D. (2009). Early contractor involvement in building procurement: contracts, partnering and project management, Chichester: John Wiley \& Sons Ltd. https://doi.org/10.1002/9781444309867

[2] Chinowsky, P. \& Songer, A. (2011). Organizational management in construction, New York: Spon Press. https://doi.org/10.4324/9780203856109

[3] Aristotel. (2006). Metaphysika (Metaphysics). Moskva: Eksmo (in Russian).

[4] Ansoff, I. (2009). Strategicheskiy menedzhment (Strategic management). Sankt-Peterburg: Piter (in Russian).

[5] Asaul, A. N. \& Ivanov, S. N. (2008). Snizhenie transaktsionnyih zatrat $v$ stroitelstve za schYot optimizatsii informatsionnogo prostranstva (Decrease in transaction costs in construction due to optimization of the information space). Sankt-Peterburg: ANO IPEV (in Russian).

[6] Rowley, J. (2002). Synergy and strategy in e-business. Marketing Intelligence and Planning, 20(4), 215-222. https://doi.org/10.1108/02634500210431603

[7] Franzsen, D., Van der Merwe, R., Buys, S., Bischoff, A. Courtney, F., Varachia, A., Cox, E., \& Miller, C. (2001). Synergies in the distribution business of Barloworld. Unpublished manuscript, Barloworld Leadership Development Programme, Gordon Institute of Business Science, Johannesburg.

[8] Naudé, A., Heyns, D., Bester, C., Puig, J. \& Tucker, G. (2002). Synergies within Barloworld. Unpublished manuscript, 
Barloworld Executive Development Programme, Gordon Institute of Business Science, Johannesburg. https://doi.org/10.1111/j.1745-6622.2009.00255.x

[9] Baldi, F., \& Trigeorgis, L. (2009). Assessing the value of growth option synergies from business combinations and testing for goodwill impairment. Journal of Applied Corporate Finance, 21(4), 115-124.

[10] DePamphilis, D. (2010). Mergers, acquisitions and other restructuring activities. Burlington: Academic Press Advanced Finance Series.

[11] Sehleanu, M. (2015). Creating or destroying value through mergers and acquisitions? Annals of the University of Oradea. Economic Science Series, 24(1), 593-600.

[12] Hamza, T., Schaier, A., \& Thraya, M. H. (2016). How do takeovers create synergies? Evidence from France. Studies in Business and Economics, 11(1), 54-72. https://doi.org/10.1515/sbe-2016-0005

[13] Shaver, M. (2006). A paradox of synergy: contagion and capacity effects in mergers and acquisitions. Academy of management review, 31(4), 962-976. https://doi.org/10.5465/amr.2006.22527468

[14] Damodaran, A. (2005). The value of synergy (working paper), New York: Stern School of Business. https://doi.org/10.2139/ssrn.841486

[15] Orekhov, S. A. (2001). Statisticheskie aspektyi issledovaniya diversifikatsii korporatsiy [Statistical aspects of research of diversification of corporations]. Moskva: INION RAN (in Russian).

[16] Basmah, A. Q. \& Rahatullah, M. K. (2013). Financial synergy in mergers and acquisitions in Saudi Arabia, Finance Challenges of the Future Yea, XIII (15), 181-192.

\author{
Authors' contacts: \\ Roman TRACH, PhD \\ Warsaw University of Life Sciences, \\ Nowoursynowska 166, 02-787 Warsaw, Poland \\ roman_trach@sggw.pl \\ Marzena LENDO-SIWICKA, PhD \\ Warsaw University of Life Sciences, \\ Nowoursynowska 166, 02-787 Warsaw, Poland \\ marzena_lendo_siwicka@sggw.pl \\ Katarzyna PAWLUK, PhD \\ Warsaw University of Life Sciences, \\ Nowoursynowska 166, 02-787 Warsaw, Poland \\ katarzyna_pawluk@sggw.pl \\ Nina BILOUS, PhD \\ National University of Water and Environmental Engineering, \\ 11 Soborna, 33028 Rivne, Ukraine \\ n.m.bilous@nuwm.edu.ua
}

